\title{
Textos e contextos educativos que promovem aprendizagem - optimização de um modelo de prática pedagógica
}

\author{
Ana Maria Morais \& Isabel Pestana Neves \\ Faculdade de Ciências da Universidade de Lisboa, Portugal
}

\begin{abstract}
Resumo
Ao longo de vinte anos de investigação, temos procurado respostas para o problema de melhorar a aprendizagem dos alunos, particularmente dos desfavorecidos, sem diminuir o nível de exigência conceptual. A investigação tem-se focado em diversos contextos: contextos de aprendizagem na família e na escola, contextos de formação de professores e contextos de construção de programas e manuais escolares. De forma a dirigir a investigação e a analisar os resultados, temos construído modelos específicos. Aproximações sucessivas conduziram a um modelo que conceptualiza uma prática pedagógica que parece ter o potencial para levar os alunos ao sucesso na escola, diminuindo o fosso entre alunos socialmente diferenciados. Os estudos têm tido como enquadramento conceptual fundamental a teoria do discurso pedagógico de Bernstein. Neste artigo pretende-se apresentar o modelo e descrever as suas características, mostrar a forma como ele tem sido usado e discutir a sua optimização. Um novo modelo teórico, derivado dessa optimização, será testado em investigação futura.
\end{abstract}

Palavras-chave

Prática pedagógica; Aprendizagem dos alunos; Contextos sociais

\section{Introdução}

O trabalho de investigação que o Grupo ESSA (Estudos Sociológicos da Sala de Aula) vem desenvolvendo há mais de vinte anos tem procurado 
encontrar respostas para o importante problema de melhorar a aprendizagem dos alunos, particularmente dos desfavorecidos, sem baixar o nível de exigência conceptual. A investigação tem-se focado em contextos de aprendizagem da família e da escola, em contextos de formação de professores e ainda em contextos de construção de currículos e programas (ex. Afonso, Morais \& Neves 2002; Afonso, Neves \& Morais, 2005; Morais \& Neves, 2003; Morais \& Neves, 2005; Neves \& Morais, 2001; Neves \& Morais, 2005; Pires, Morais \& Neves, 2004). A aprendizagem dos alunos tem sido estudada ao longo de todo o sistema educativo, desde o jardim-de-infância ao ensino superior, e tem-se, fundamentalmente, centrado na educação científica. Têm sido construídos diversos modelos para dirigir a investigação e também para analisar os resultados obtidos. Ao longo de todo o processo de investigação, chegou-se à conceptualização de um modelo de prática pedagógica da escola que parece ter o potencial para levar os alunos ao sucesso, diminuindo o fosso entre alunos de origens sociais diferenciadas.

Embora a investigação que tem vindo a ser desenvolvida tenha em conta perspectivas das áreas da epistemologia e da psicologia, é a teoria do discurso pedagógico de Bernstein $(1990,2000)$ que tem fornecido a principal estrutura conceptual dos estudos efectuados. O seu poder de descrição, explicação, diagnóstico, previsão e transferência tem permitido realizar investigação mais rigorosa, no sentido de produzir novo conhecimento na área da educação.

Este artigo tem os seguintes objectivos: (a) apresentar o modelo de prática pedagógica da escola e descrever as suas características; (b) mostrar de que forma o modelo tem sido usado em contexto escolar; (c) explicar de que modo o modelo pode ser estendido a contextos de formação de professores e de construção de currículos e programas; e (d) discutir a optimização do modelo.

\section{Modelo de prática pedagógica da escola}

O diagrama apresentado na Figura 1 mostra as principais características do modelo de prática pedagógica que resultou da investigação realizada. 


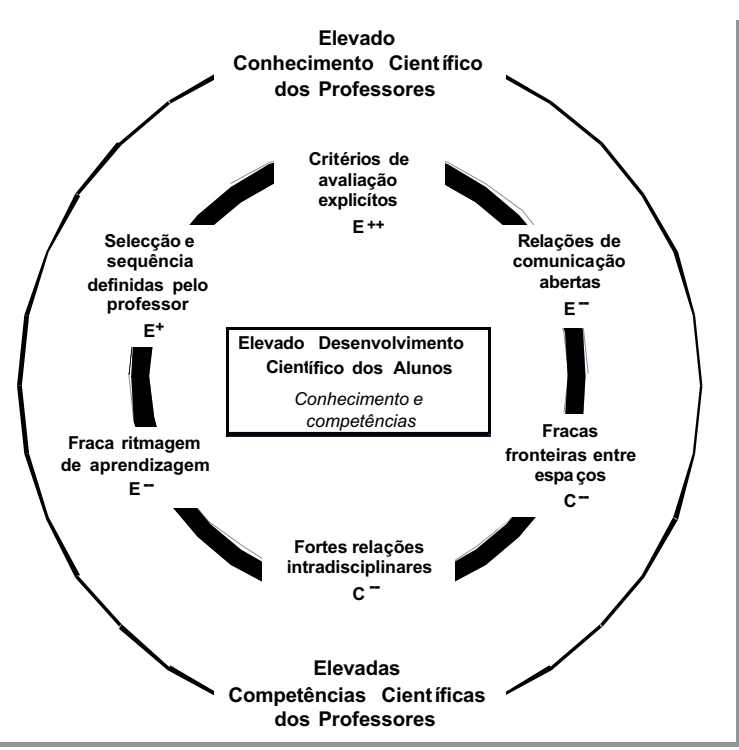

Figura 1 - Relações entre as características da prática pedagógica e o desenvolvimento científico

As principais características sociológicas da modalidade de prática pedagógica que têm mostrado ser fundamentais para a aprendizagem científica de todos os alunos são as seguintes:

- Distinção clara entre sujeitos com estatutos distintos Classificação forte na relação professor-aluno.

- Selecção e sequência de conhecimento, competências e actividades controladas pelo professor - Enquadramento forte da selecção e da sequência, particularmente ao macro nível.

- Tempo de aquisição controlado pelos alunos - Enquadramento fraco ao nível da ritmagem.

- Explicitação clara do texto legítimo a ser adquirido no contexto da sala de aula - Enquadramento forte ao nível dos critérios de avaliação.

- Relações abertas de comunicação entre o professor e os alunos e entre os próprios alunos - Fraco enquadramento ao nível das regras hierárquicas. 
- Interrelação entre os diversos conhecimentos, de uma dada disciplina, a serem aprendidos pelos alunos - Classificação fraca ao nível da intradisciplinaridade.

- Esbatimento das fronteiras entre os espaços professor-aluno e aluno-aluno - Classificação fraca entre espaços.

Além destas características, os estudos têm também sugerido a importância, para a aprendizagem dos alunos, da relação do seu conhecimento e das suas experiências com o conhecimento a ser adquirido, tendo o último maior estatuto, isto é, de uma relação escola-comunidade caracterizada por forte classificação e fraco enquadramento.

De acordo com a investigação realizada, estas características podem conduzir os alunos a um desenvolvimento científico elevado em termos de conhecimento e competências. Contudo, tal desenvolvimento só poderá ocorrer se os professores possuírem um elevado nível de conhecimento e competências científicas, o que significa que não há metodologias óptimas que possam compensar uma proficiência científica pobre.

Esta investigação iniciou-se com um estudo que foi planificado com o objectivo de comparar o efeito de três práticas pedagógicas distintas na aprendizagem científica dos alunos. Duas das práticas correspondiam, em termos gerais, aos dois extremos do processo de ensino-aprendizagem modelo tradicional, de classificações e enquadramentos gerais fortes, e modelo progressista, de classificações e enquadramentos gerais fracos; a terceira prática situava-se no meio em termos das relações de poder e de controlo entre o professor e os alunos (Morais, Neves, Medeiros, Peneda, Fontinhas \& Antunes, 1993). Ao longo deste estudo foi-se tendo a percepção de que uma prática pedagógica que produziria efeitos positivos, em termos da aprendizagem dos alunos, seria uma prática em que quer o professor quer os alunos teriam o controlo de acordo com características específicas da prática e em que o poder seria detido pelo professor. Por exemplo, já era claro na altura que os critérios de avaliação deveriam ser explícitos (forte enquadramento) e que as regras hierárquicas deveriam ser reguladas por um fraco enquadramento, isto é, já era claro que uma característica do modelo tradicional e uma característica do modelo progressista deveriam estar conjuntamente presentes na mesma prática. Começou-se então a 
desenvolver estudos que recorressem a práticas pedagógicas mistas, experimentando várias combinações das diferentes características que definem os contextos organizacional e interaccional da sala de aula (ex. Neves \& Morais, 2001; Pires, Morais \& Neves, 2004; Rocha \& Morais, 1999). Estes estudos focaram-se em diversas amostras de diversos níveis de escolaridade e usaram uma variedade de metodologias que, no conjunto, constituíam uma abordagem metodológica mista (Morais \& Neves, 2007). Ao longo deste processo de investigação foi possível chegar à conceptualização de uma prática pedagógica mista com as características indicadas anteriormente.

\section{O modelo em acção}

Nesta secção do artigo, pretende-se mostrar de que modo o modelo tem funcionado nos estudos desenvolvidos. Seleccionou-se, como exemplo, um estudo que foi realizado ao nível do primeiro ciclo do ensino básico e no qual foram implementadas, na área das ciências, duas práticas pedagógicas distintas, por dois professores de duas escolas, numa amostra total de 26 crianças (Morais, Neves, Silva \& Deus, 2005; Silva, Morais \& Neves, 2005). Elaborou-se um livro de actividades, com guia para o professor, que foi fornecido aos professores de modo a ajudá-los a conduzir as crianças a adquirir conhecimento ("o crescimento dos seres vivos") e a desenvolver competências investigativas. Subjacente a estas actividades estava o modelo de prática pedagógica mista derivado de estudos anteriores.

Foi construído um instrumento para ser utilizado na caracterização das práticas pedagógicas dos professores (Silva, Morais \& Neves, 2003). Esse instrumento continha, para as várias características da prática pedagógica, nos contextos instrucional e regulador, indicadores através dos quais a prática podia ser caracterizada em escalas de quatro graus de classificação e enquadramento. Mostra-se, em anexo, como exemplo, a parte do instrumento que se refere aos critérios de avaliação e à intra-disciplinaridade. Com base nesse instrumento, analisaram-se as transcrições dos registos áudio e vídeo do processo de ensino-aprendizagem que teve lugar nas duas escolas. A caracterização das duas práticas pedagógicas está apresentada na Tabela I. 


\section{Tabela I - Caracterização de duas práticas pedagógicas no $1^{\circ}$ ciclo do ensino básico}

\begin{tabular}{|c|c|c|c|c|}
\hline & \multicolumn{2}{|c|}{ Escola Arco-Íris } & \multicolumn{2}{|c|}{ Escola Tulipa } \\
\hline & nível macro & nível micro & nível macro & nível micro \\
\hline \multicolumn{5}{|l|}{ Regras Discursivas } \\
\hline selecção & $\mathrm{E}^{++}$ & $E^{+} / E^{-}$ & $\mathrm{E}^{++}$ & $\mathrm{E}^{++} / \mathrm{E}^{+}$ \\
\hline sequência & $\mathrm{E}^{++}$ & $\mathrm{E}^{+} / \mathrm{E}^{-}$ & $\mathrm{E}^{++}$ & $\mathrm{E}^{++} / \mathrm{E}^{+}$ \\
\hline ritmagem & $E^{--/} E^{-}$ & $E^{-/} E^{--}$ & $\mathrm{E}^{+}$ & $\mathrm{E}^{+}$ \\
\hline Critérios de avaliação & $\mathrm{E}^{++}$ & $\mathrm{E}^{++}$ & $E^{-}$ & $E^{-}$ \\
\hline \multicolumn{5}{|l|}{ Relação entre discursos } \\
\hline relações intradisciplinares & \multicolumn{2}{|c|}{$\mathrm{C}^{--}$} & \multicolumn{2}{|c|}{$\mathrm{C}^{+}$} \\
\hline relações interdisciplinares & \multicolumn{2}{|c|}{$\mathrm{C}^{-} / \mathrm{C}^{--}$} & \multicolumn{2}{|c|}{$\mathrm{C}^{+} / \mathrm{C}^{++}$} \\
\hline Relação escola - comunidade & \multicolumn{2}{|c|}{$\mathrm{C}^{++} \mathrm{E}^{--} / \mathrm{E}^{-}$} & \multicolumn{2}{|c|}{$C^{++} E^{+} / E^{-}$} \\
\hline \multicolumn{5}{|l|}{ Regras hierárquicas } \\
\hline relação professor - aluno & \multicolumn{2}{|c|}{$E^{-} / E^{--}$} & \multicolumn{2}{|c|}{$E^{+} / E^{++}$} \\
\hline relação aluno - aluno & \multicolumn{2}{|c|}{$E^{-}$} & \multicolumn{2}{|c|}{$E^{+} / E^{-}$} \\
\hline \multicolumn{5}{|l|}{ Relações entre espaços } \\
\hline espaços professor - aluno & $\mathrm{C}^{-}$ & $C^{-} / C^{+}$ & $\mathrm{C}^{-}$ & $c^{-}$ \\
\hline espaços aluno - al uno & $\mathrm{C}^{+} / \mathrm{C}^{-}$ & $\mathrm{C}^{+}$ & $\mathrm{C}^{-}$ & $\mathrm{C}^{+}$ \\
\hline
\end{tabular}

Os dados apresentados na tabela evidenciam diferenças entre as práticas dos dois professores. O professor da escola Arco-Íris implementou uma prática que está de acordo com o modelo de prática mista que havia sido proposto, enquanto a professora da escola Tulipa implementou uma prática que se distancia desse modelo. Se nos concentrarmos em duas características específicas da prática - critérios de avaliação e intradisciplinaridade - pode dizer-se que o professor da escola Arco-Íris tornou os critérios de avaliação muito explícitos quer ao macro quer ao micro nível (enquadramento muito forte: $\mathrm{E}^{++}$) e estabeleceu relações fortes de intradisciplinaridade entre os diferentes conhecimentos (classificação muito fraca: $\mathrm{C}^{--}$); pelo contrário, a professora da escola Tulipa deixou os critérios de avaliação implícitos aos dois níveis (enquadramento fraco: $\mathrm{E}^{-}$) e estabeleceu relações fracas entre os diferentes conhecimentos (classificação forte $\mathrm{C}^{+}$). A observação da tabela no seu conjunto mostra que este padrão de diferença 
entre os dois professores se mantém, em geral, para todas as características da prática pedagógica.

Os excertos que se seguem ilustram alguns valores de classificação e enquadramento, atribuídos às práticas pedagógicas dos dois professores, no que diz respeito às duas características referidas e quando se considera o indicador construção de sínteses.

\section{Excertos}

[...] Se os pintainhos não tivessem tido alimento tinham crescido? [discussão com as crianças] Então cresceram [os seres vivos] em quaisquer condições? [discussão com as crianças] Não. Não crescem. Precisam de condições especiais para crescer, ou seja, as plantas precisam de água, os animais precisam de comida....alimento, então não crescem em quaisquer condições [...]. Professor da Escola Arco-Íris

A professora lê as frases do livro de actividades:

[...] ao longo do ano observámos mudanças em sementes, no pinto, nos bichosda-seda e, claro, no teu próprio corpo. Verificámos que mudaram, está bem?[...] cresceram, cresceram. Então vamos escrever cresceram aí no primeiro espaço. Vá! Já escreveram?

Aprendemos então que quando as coisas crescem estão...vivas, então escrevam vivas... já está? Professora da Escola Tulipa

O primeiro excerto evidencia a existência de relações intradisciplinares muito fortes $\left(\mathrm{C}^{--}\right)$, já que são integrados conceitos distintos do tema em estudo ("crescimento dos seres vivos"), e critérios de avaliação explícitos $\left(\mathrm{E}^{++}\right)$, já que a síntese é clara e construída com as crianças. $\mathrm{O}$ segundo excerto evidencia relações intra-disciplinares fracas $\left(\mathrm{C}^{+}\right)$, já que apenas factos distintos do tema são relacionados, e critérios de avaliação implícitos $\left(\mathrm{E}^{-}\right)$, já que a professora diz às crianças o que devem escrever sem explicar o respectivo significado.

De forma a avaliar o efeito das duas práticas na aprendizagem das crianças, utilizou-se o conceito de código de Bernstein. A aprendizagem foi, assim, apreciada em função da orientação específica de codificação (OEC) das crianças para o contexto específico da compreensão de conceitos, isto é, foi apreciada a sua posse de regras de reconhecimento e de realização para 
aquele contexto. Com este objectivo, aplicou-se uma entrevista semiestruturada às crianças, antes e depois do processo de aprendizagem, e para a qual se construiu um guião específico. A Figura 2 apresenta os resultados da entrevista, quando se consideram três níveis de desempenho das crianças, em termos de OEC, e a composição social das escolas. Os resultados evidenciam diferenças importantes entre os dois grupos de crianças. A evolução das crianças da Escola Arco-Íris foi maior do que a evolução das crianças da Escola Tulipa, sendo essa diferença uma consequência da evolução diferencial das crianças da classe trabalhadora das duas escolas. Este resultado é particularmente relevante uma vez que estudos anteriores (e.g. Domingos, 1987) têm mostrado que as crianças da classe trabalhadora estão em dupla desvantagem quando aprendem em escolas da classe trabalhadora, como é o caso da Escola Arco-Íris.

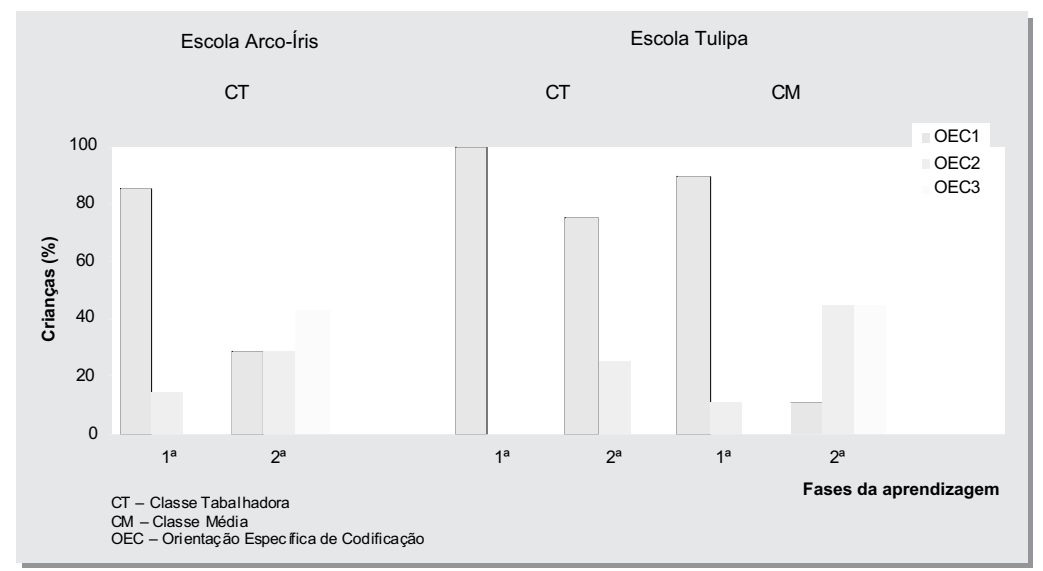

Figura 2 - Evolução da orientação específica de codificação nas duas escolas

É claro, a partir dos resultados, que o professor que desenvolveu uma prática pedagógica mais próxima do modelo que tem vindo a ser referido levou as suas crianças a atingir um grau mais elevado de literacia científica quando comparado com a professora cuja prática pedagógica se distanciou desse modelo. Os resultados obtidos mostram ainda que a prática pedagógica pode ultrapassar o efeito da classe social, o que constitui uma 
conclusão de particular importância em termos do papel que a escola pode ter no esbatimento das diferenças entre grupos sociais.

O reduzido tamanho da amostra deste estudo podia levar-nos a pensar que estas conclusões não são válidas. Contudo, o facto destes resultados confirmarem resultados de estudos anteriores desenvolvidos com amostras diversas de níveis escolares diversos aumenta o grau de validade dos estudos como um todo. É importante notar que este tipo de estudos requer profundidade e rigor a todos os níveis da investigação, algo que não é possível conseguir com grandes amostras.

Embora o modelo de prática pedagógica a que se chegou tenha mostrado ser eficaz em aumentar o nível de competências e conhecimentos científicos dos alunos e em diminuir o fosso entre alunos de origens sociais diferenciadas, a investigação desenvolvida também tem fornecido informação para afirmar que se poderá ir mais longe. Tratar-se-á deste assunto na última secção do artigo.

\section{Extensão do modelo a outros contextos educacionais}

Nesta secção descrevem-se dois estudos, um deles semelhante ao estudo que se acabou de descrever, mas desenvolvido ao nível do ensino superior e o outro focado no contexto de currículos e programas. Com o primeiro estudo pretende-se mostrar de que forma o modelo pode ser aplicado a níveis distintos de escolaridade e com o segundo estudo mostrar a sua aplicação a contextos diferentes dos contextos de ensino-aprendizagem.

\section{O modelo num contexto de ensino superior}

O estudo desenvolvido no contexto do ensino superior focou-se na disciplina de Didáctica das Ciências em licenciaturas de educação científica (Santos, 2007). Pretendia-se ver em que medida o modelo de prática pedagógica a que se tinha chegado, através de investigação nos níveis mais baixos de escolaridade, poderia funcionar no ensino superior, no sentido de promover a aprendizagem de alunos universitários. Estudaram-se duas práticas pedagógicas desenvolvidas por duas professoras em duas turmas distintas e analisou-se a aprendizagem dos alunos através da sua orientação específica de codificação para conhecimentos seleccionados da disciplina. 
Construiu-se, também neste caso, um instrumento para caracterizar a prática pedagógica que é paralelo ao instrumento do estudo anteriormente descrito (ver anexo), embora adaptado ao novo contexto (Santos \& Morais, 2006).

Os excertos que se seguem foram extraídos das transcrições das aulas e referem-se ao indicador construção de sínteses da regra discursiva critérios de avaliação.

\section{Excertos}

$\mathrm{E}^{++}[\ldots]$ fazer a síntese daquilo que andámos a trabalhar durante estas três aulas [...] o que é que a gente poderia dizer que aprendeu? [a professora discute com os alunos todos os pontos relevantes e termina com uma conclusão estruturada, escrita num acetato]: "A ciência, enquanto corpo organizado de conhecimentos em constante evolução, é o resultado de um processo dinâmico de resolução de problemas, que envolve um conjunto não linear de etapas interligadas em que o trabalho laboratorial desempenha um papel crucial". [...] esta é a ideia mais geral [...] há outras pequenas ideias que fomos construindo a pouco e pouco [...]

(sínteses claras, construídas com os alunos e registadas).

$\mathrm{E}^{+}[\ldots]$ podemos dizer como síntese das três aulas que [...] [a professora apresenta a conclusão escrita num acetato]: "O grau de complexidade dos conhecimentos científicos e metacientíficos e das competências cognitivas, bem como o grau de relação intradisciplinar entre os conhecimentos científicos traduzem o nível de exigência conceptual do ensino/aprendizagem, sendo este nível tanto mais elevado quanto maior for o grau de complexidade dos conhecimentos e das competências e o grau de relação intradisciplinar". [...] ao planificarmos o ensino/aprendizagem com base nos conteúdos e nos objectivos tínhamos de ter em atenção que há vários graus de complexidade e que o ensino não se deve cingir aos de baixo nível de complexidade (sínteses claras, construídas pela professora e registadas).

E- [...] O que é que nós queremos ensinar aos nossos alunos? [...] (os alunos começam a arrumar os seus materiais, sem tomarem quaisquer notas do que a professora está a dizer) É a linguagem das competências que eu quero que aprendam aqui. São competências dessas que vocês disseram aqui que nós vamos ter que desenvolver nos nossos alunos. Tem a ver com raciocínio, tem a ver com atitudes, tem a ver com mobilização do conhecimento científico, tem a ver com os processos da ciência, é isso tudo

(sínteses nada claras, construídas pela professora e não registadas).

Estes excertos evidenciam também graus distintos de intradisciplinaridade. O primeiro e o segundo excertos podem ser classificados com grau $\mathrm{C}^{-}$, já que correspondem a sínteses que fazem uma 
relação entre diversos conceitos de um determinado tema em estudo. $\mathrm{O}$ terceiro excerto pode ser classificado como $\mathrm{C}^{++}$, uma vez que corresponde a uma síntese que apresenta conhecimento factual de um determinado tema.

Por limitações de espaço, os resultados que se referem à caracterização da prática e à orientação específica de codificação dos alunos não serão apresentados neste artigo.

\section{O modelo num contexto de currículos e programas}

Um dos estudos desenvolvidos neste contexto centrou-se na actual reforma educativa do ensino básico (Ferreira, 2007) e é parte de uma investigação mais ampla que pretendia analisar os processos de recontextualização que ocorrem no campo de recontextualização oficial e entre este campo e o campo de recontextualização pedagógica. A análise que se apresenta foca-se nos currículos e programas, enquanto textos produzidos no campo de recontextualização oficial, particularmente nos dois principais documentos curriculares - Competências Essenciais e Orientações Curriculares. As análises centraram-se no tema "Sustentabilidade da Terra" da disciplina de Ciências Naturais e incidiram em aspectos específicos relacionados com o que e com o como dos processos educativos: construção da ciência; nível de exigência conceptual; intradisciplinaridade e critérios de avaliação (quanto à relação Ministério da Educação-professores). Para cada um destes aspectos foram construídos instrumentos organizados de forma a contemplar as quatro secções principais dos programas (Conhecimentos, Finalidades, Orientações Metodológicas e Avaliação), e que continham, para cada secção, quatro escalas de classificação e/ou de enquadramento e respectivos descritivos (ex. Alves, Calado, Ferreira, Morais \& Neves, 2006; Ferreira, Alves, Calado, Morais \& Neves, 2006). A análise exigiu que o texto dos dois documentos curriculares fosse dividido em unidades de análise, que foram constituídas por excertos do texto com um dado significado semântico.

A Tabela II mostra, para a Secção Finalidades, o instrumento de análise das relações intra-disciplinares. Seguem-se exemplos de excertos (unidades de análise) dos documentos analisados que ilustram diferentes graus de classificação quanto à relação intra-disciplinar. 
Tabela II - Relações intradisciplinares nos programas de Ciências Naturais - Secção do instrumento

\begin{tabular}{|c|c|c|c|c|}
\hline Secções & $\mathrm{C}^{++}$ & $\mathrm{C}^{+}$ & $\mathrm{C}^{-}$ & $\mathrm{C}^{--}$ \\
\hline Finalidades & $\begin{array}{l}\text { Contemplam } \\
\text { apenas a relação } \\
\text { entre conteúdos de } \\
\text { ordem simples } \\
\text { dentro do mesmo } \\
\text { tema. } \\
\text { Ou } \\
\text { É omisso } \\
\text { conhecimento } \\
\text { científico } \\
\text { indispensável à } \\
\text { compreensão da } \\
\text { relação entre } \\
\text { conteúdos dentro } \\
\text { do mesmo tema. }\end{array}$ & $\begin{array}{l}\text { Contemplam a } \\
\text { relação entre } \\
\text { conteúdos de } \\
\text { ordem simples de } \\
\text { temas diferentes. } \\
\text { Ou } \\
\text { É omisso } \\
\text { conhecimento } \\
\text { científico } \\
\text { indispensável à } \\
\text { compreensão da } \\
\text { relação entre } \\
\text { conteúdos de } \\
\text { temas diferentes. }\end{array}$ & $\begin{array}{l}\text { Contemplam a } \\
\text { relação entre } \\
\text { conteúdos de } \\
\text { ordem complexa, } \\
\text { ou entre estes e } \\
\text { conteúdos de } \\
\text { ordem simples, } \\
\text { dentro do mesmo } \\
\text { tema. }\end{array}$ & $\begin{array}{l}\text { Con templam a } \\
\text { relação entre } \\
\text { conteúdos de } \\
\text { ordem complexa, } \\
\text { ou en tre estes e os } \\
\text { conteúdos de } \\
\text { ordem simples, de } \\
\text { temas diferentes. }\end{array}$ \\
\hline
\end{tabular}

\section{Excertos}

\section{Intradisciplinaridade}

$\mathrm{C}^{++}$Recomenda-se que nesta temática os alunos compreendam a existência de diferentes tipos de águas e a relação com a sua utilização para fins diversos. (Orientações Curriculares, p. 28)

C- Compreensão de que a dinâmica dos ecossistemas resulta de uma interdependência entre seres vivos, materiais e processos. (Competências Essenciais, p. 142)

$\mathrm{C}^{--}$Outro aspecto a salientar tem a ver com a articulação dos temas. Com a sequência sugerida pretende-se que, após terem compreendido conceitos relacionados com a estrutura e funcionamento do sistema Terra, os alunos sejam capazes de os aplicar em situações que contemplam a intervenção humana na Terra [...] visando a sustentabilidade na Terra. (Competências Essenciais, pp. 134-135)

A Tabela III mostra, para a secção Orientações Metodológicas, o instrumento de análise dos critérios de avaliação, relacionado com o conhecimento "dimensão sociológica externa da construção da ciência". Seguem-se exemplos de unidades de análise dos documentos curriculares que ilustram diferentes graus de enquadramento quanto aos critérios de avaliação. 


\section{Tabela III - Critérios de avaliação para o conhecimento "dimensão sociológica externa da ciência" presente nos programas de Ciências Naturais - Secção do instrumento}

\begin{tabular}{|c|c|c|c|c|}
\hline Secções & $E^{++}$ & $\mathbf{E}^{+}$ & $E^{-}$ & $E^{--}$ \\
\hline $\begin{array}{l}\text { Orientações } \\
\text { metodológicas }\end{array}$ & $\begin{array}{l}\text { São apresentadas } \\
\text { estratégias/ } \\
\text { metod ologias } \\
\text { destinadas à } \\
\text { transmissão/ } \\
\text { aquisição de } \\
\text { conteúdos relativos } \\
\text { à dimensão } \\
\text { sociológica externa } \\
\text { da ciência. } \\
\text { É explicado o } \\
\text { significado dessas } \\
\text { estratégias no } \\
\text { âmbito do ensi no/ } \\
\text { aprendizagem da } \\
\text { metaciência, sendo } \\
\text { também referida a } \\
\text { importância desta } \\
\text { no ensino das } \\
\text { ciências, de acordo } \\
\text { com a perspectiva } \\
\text { do currículo. }\end{array}$ & $\begin{array}{l}\text { São apresentadas } \\
\text { estratégias / } \\
\text { metodologias } \\
\text { destinadas à } \\
\text { transmissão/ } \\
\text { aquisição de } \\
\text { conteúdos relativos } \\
\text { à dimensão } \\
\text { sociológica externa } \\
\text { da ciência. } \\
\text { É explicado o } \\
\text { significado dessas } \\
\text { estratégias no } \\
\text { âmbito do ensi no/ } \\
\text { apren dizagem da } \\
\text { metaciência, sendo } \\
\text { também referida a } \\
\text { importância desta } \\
\text { no ensino das } \\
\text { ciências em geral } \\
\text { (sem referir a } \\
\text { perspectiva de } \\
\text { ensino das ciências } \\
\text { que o currículo } \\
\text { defende). }\end{array}$ & $\begin{array}{l}\text { São apresentadas } \\
\text { estr atégias / } \\
\text { metodologias } \\
\text { destinadas à } \\
\text { transmissão/ } \\
\text { aquisição de } \\
\text { conte údos relativos } \\
\text { à dimensão } \\
\text { sociológica externa } \\
\text { da ciência, mas } \\
\text { não é explicado o } \\
\text { significado dessas } \\
\text { estr atégias/ } \\
\text { metodologias. }\end{array}$ & $\begin{array}{l}\text { São apresentadas } \\
\text { estratégias / } \\
\text { metodologias } \\
\text { destinadas à } \\
\text { transmissão/ } \\
\text { aquisição de } \\
\text { conteúdos relativos } \\
\text { à dimensão } \\
\text { sociológica externa } \\
\text { da ciência de forma } \\
\text { muito genérica. }\end{array}$ \\
\hline
\end{tabular}

\section{Excertos}

\section{Critérios de Avaliação}

$\mathrm{E}^{-} \mathrm{A}$ este nível sugere-se a discussão de problemáticas reais, como por exemplo os acidentes em centrais nucleares, a adição de chumbo à gasolina [...]. Estas problemáticas poderão constituir oportunidade para discussão sobre questões de natureza social e ética que permitam aos alunos momentos de reflexão a propósito dos prós e contras de algumas inovações científicas para o indivíduo, para a sociedade e para o ambiente [não são fornecidas explicações adicionais] (Orientações Curriculares, p. 30).

$\mathrm{E}^{--}$É recomendada a realização de visitas de estudo a unidades industriais existentes na região e a correspondente análise dos custos, benefícios e riscos sociais e ambientais associados à actividade industrial [não são fornecidas explicações adicionais] (Orientações Curriculares, p. 28).

Nos documentos curriculares analisados não estavam presentes unidades de análise correspondentes aos graus $\mathrm{E}^{++}$e $\mathrm{E}^{+}$, o que significa que os critérios de avaliação nunca eram explícitos. 
Os resultados da análise dos dois documentos do currículo (Competências Essenciais e Orientações Curriculares), quanto às relações de intradisciplinaridade e aos critérios de avaliação, estão expressos respectivamente nos gráficos das figuras 3 e 4 . Em ambas as figuras, os resultados estão organizados em função de cada uma das quatro secções dos documentos e da totalidade das secções.

Figura 3 - Relações intradisciplinares nos programas de Ciências Naturais

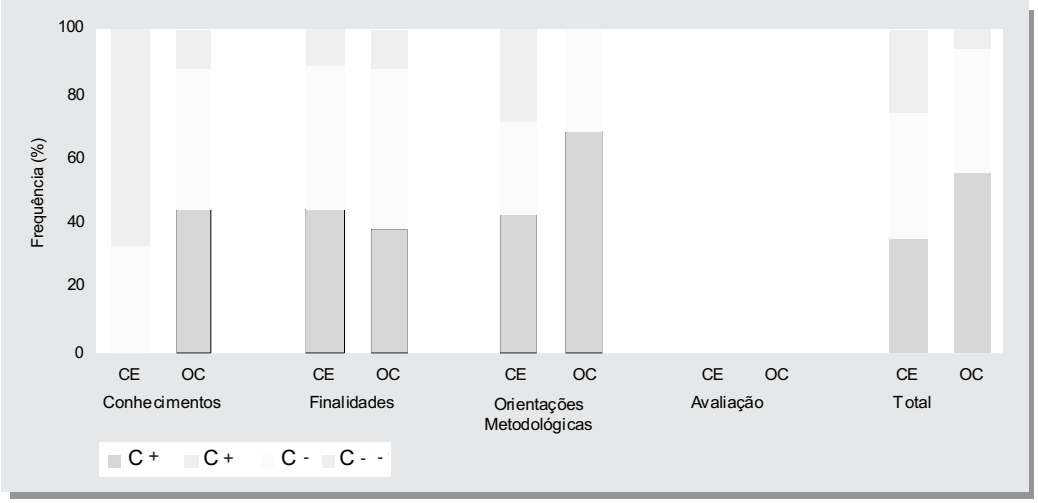

Figura 4 - Critérios de avaliação para o conhecimento "dimensão sociológica externa da ciência" nos programas de Ciências Naturais

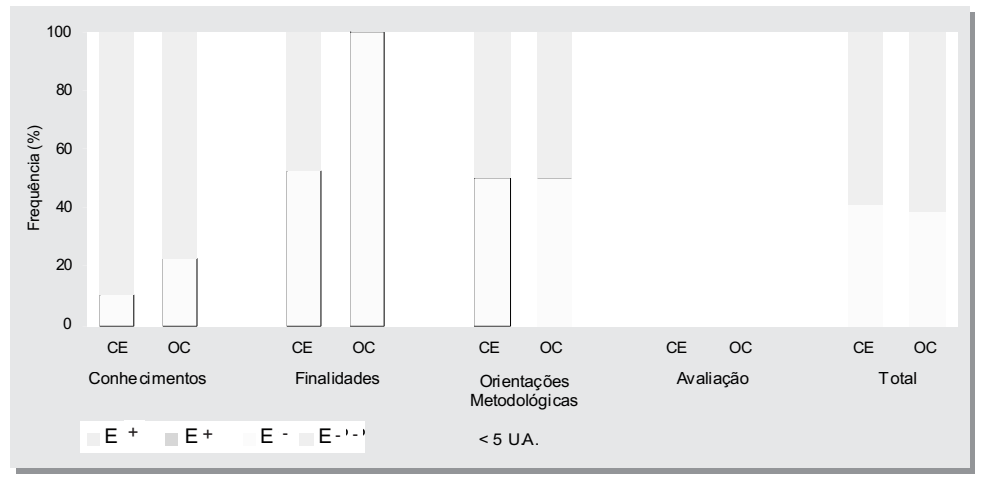


Resumidamente, pode-se dizer que, em geral, o valor relativo atribuído às relações de intradisciplinaridade entre os conhecimentos científicos decresceu quando se passa do documento Competências Essenciais (CE) para o documento Orientações Curriculares (OC), o que evidencia uma recontextualização, que tem lugar dentro do campo de recontextualização oficial, da mensagem contida no discurso pedagógico oficial. Como consequência, os professores irão receber duas mensagens diferentes e, se seguirem unicamente as orientações curriculares, poderão ser levados a dar pouca valorização à intradisciplinaridade nas suas práticas pedagógicas.

No que se refere aos critérios de avaliação, pode-se dizer, também de forma resumida, que, mesmo quando a construção da ciência está presente nos documentos curriculares, como é o caso da dimensão sociológica externa da ciência, a mensagem sobre o processo de construção da ciência está implícita e, em muitos casos, totalmente implícita $\left(E^{--}\right)$. Como consequência, os professores poderão ignorá-la ou não serem capazes de a introduzir nas suas práticas pedagógicas.

Os trabalhos de investigação que foram descritos mostram de que modo é possível estudar textos e contextos diferenciados utilizando as mesmas relações e conceitos teóricos. Isto torna possível estabelecer comparações ao longo do sistema educativo, contribuindo assim para aumentar o nível de conceptualização das conclusões.

\section{Optimização do modelo}

Como foi dito anteriormente, o modelo resultou dos muitos estudos que têm vindo a ser desenvolvidos e, por essa razão, poder-se-á ter alguma confiança nas conclusões a que se tem chegado. Contudo, considera-se que há necessidade de ir muito mais além na investigação, de modo a que o modelo a que se chegou alcance um grau mais elevado de precisão, de modo a aumentar o rigor da investigação futura e o poder de transferência para a área do desenvolvimento curricular e para a prática em sala de aula.

Assim, pretende-se, com base no actual modelo, construir um novo modelo teórico para ser testado em investigação futura. Esse modelo irá conter hipóteses que, baseadas em resultados anteriores ou teoricamente desenvolvidas, serão focadas nos pontos fracos do modelo anterior. 
Em primeiro lugar, há duas características da prática pedagógica relação escola-comunidade e relações interdisciplinares - que necessitam ser estudadas com maior profundidade. No primeiro caso, tem-se partido sempre do pressuposto que a classificação entre discursos, isto é, entre o conhecimento da escola e o conhecimento do dia-a-dia, deve ser muito forte dado que o primeiro deve ter o maior estatuto. Contudo, entende-se que a aprendizagem dos alunos poderá ser melhorada quando se deixa entrar, na escola, os seus conhecimentos e experiências, o que significa defender uma relação de comunicação entre a escola e a comunidade. A relação escolacomunidade tem, assim, sido caracterizada não só através da classificação mas também do enquadramento, embora o enquadramento tenha aqui um significado ambíguo uma vez que não se refere à relação entre sujeitos. Este aspecto necessita claramente de ser melhor estudado.

No caso da interdisciplinaridade, tem-se partido sempre do pressuposto generalizado de que o esbatimento das fronteiras entre disciplinas é favorável à aprendizagem dos alunos mas, na prática, a investigação tem sido sempre desenvolvida ou em contextos onde uma dada disciplina de ciências está institucionalmente separada de outras disciplinas da escola ou em contextos onde esse isolamento foi intencionalmente criado, como nos casos dos estudos realizados aos níveis do jardim-de-infância ou do primeiro ciclo do ensino básico. Estes estudos resultaram da tentativa de levar os professores envolvidos na investigação a concentrarem-se nas ciências em contextos onde, tradicionalmente, se atribui baixo estatuto a esta área do conhecimento. Contudo, em alguns estudos estabeleceu-se alguma relação com outras disciplinas, como a matemática e o português, o que significa que, quando se caracterizou a prática pedagógica, foi possível atribuir o valor $\mathrm{C}^{-}$à interdisciplinaridade, numa escala de quatro graus de classificação entre as várias disciplinas da escola. Nos estudos desenvolvidos não há evidência de que este esbatimento das fronteiras entre disciplinas seja favorável à aprendizagem dos alunos ou, melhor dizendo, não tem sido possível, até ao momento, identificar esta característica como sendo favorável à aprendizagem dos alunos. De um ponto de vista teórico, poderia mesmo defender-se o oposto, uma vez que, sendo os alunos socializados, através de toda a sua vida académica, em classificações fortes entre diferentes disciplinas, poderão ter maior dificuldade em aprender todas as disciplinas 
num contexto de inter-relação. Dado que a interdisciplinaridade aumenta o nível de abstracção, será também mais difícil abordá-la enquanto não houver alguma proficiência em áreas separadas do conhecimento. Para além disso, os alunos desfavorecidos poderão encontrar particulares dificuldades em aprender em contextos interdisciplinares, dado que tendem a ser primariamente socializados em ambientes de fortes classificações. Este aspecto da prática pedagógica necessita, assim, de mais atenção no futuro.

A outra área de optimização do modelo refere-se aos indicadores seleccionados para cada uma das características da prática pedagógica. Os indicadores têm variado de acordo com o estudo que está a ser desenvolvido. Por exemplo, os indicadores para a regra discursiva selecção diferem de um contexto de jardim-de-infância para um contexto de ensino superior. Contudo, alguns indicadores têm sido comuns a todos os contextos, como é o caso do indicador "elaboração de sínteses", pois tem-se considerado que eles são importantes para caracterizar a prática pedagógica presente em qualquer contexto. Tem-se procurado seleccionar uma amostra de indicadores que sejam relevantes e representativos de um conjunto vasto de indicadores que podem ser estabelecidos para caracterizar a prática pedagógica; contudo, essa selecção necessita ser mais rigorosa. Além disso, pretende-se caminhar no sentido de reduzir o número de indicadores, tentando encontrar quais deles são suficientemente poderosos para representar a totalidade de uma dada característica da prática pedagógica, e tornar mais precisos e concisos os descritivos referentes aos indicadores mais relevantes. Esta medida será útil para a investigação futura e, mais importante, ao permitir aumentar o poder de transferência dos resultados de investigação para a prática educacional, tornará mais fácil o seu uso pelos professores e por aqueles que se dedicam ao desenvolvimento curricular. Será também importante descobrir se deverão ser mantidos, nas análises, indicadores específicos para os macro e micro níveis da prática pedagógica, ou se os indicadores de um desses níveis poderão ser tomados como representativos de ambos os níveis. Outro aspecto que necessita ser mais desenvolvido é a pesquisa de indicadores que possam ser comuns a todas as características da prática pedagógica, como por exemplo aos critérios de avaliação e às regras hierárquicas. Isto é algo que se tem tentado fazer, mas que, até agora, se tem sentido que nem sempre é fácil de atingir. 
Outro aspecto importante que se entende dever ser considerado em estudos futuros refere-se à necessidade de estudar uma característica da prática pedagógica de cada vez, controlando os valores de todas as outras características. Isto revela-se particularmente relevante para as características da prática que têm sido menos estudadas. Por exemplo, se quisermos descobrir quão importante é a interdisciplinaridade para a aprendizagem, dever-se-á analisar a influência de diferentes valores desta característica mantendo os valores das outras características iguais em todas as turmas da amostra da investigação. Contudo, este procedimento não deverá interferir com o procedimento mais amplo, referido anteriormente, em que se começa por construir um modelo e se estuda, depois, como é que ele resulta na prática.

É importante notar que durante toda a investigação se tornou claro que algumas características da prática pedagógica estão de tal forma interligadas que os valores de classificação e/ou enquadramento de uma dada característica podem determinar os valores de outras. Por exemplo, critérios de avaliação explícitos (enquadramento muito forte) requerem que os alunos tenham controlo na ritmagem (enquadramento muito fraco), de forma a que haja tempo para explicitar os critérios, e requerem que os alunos tenham controlo ao nível das regras hierárquicas (enquadramento muito fraco), de modo a que os alunos possam levantar questões livremente e verem as suas dúvidas discutidas.

Um aspecto fundamental, de ordem diferente, que se pretende ter em conta em investigação futura, está relacionado com a proficiência científica dos professores em termos de conhecimento e de competências. Os estudos desenvolvidos têm mostrado que muitos professores não possuem competências e conhecimento científicos, particularmente os professores do jardim-de-infância e do primeiro ciclo do ensino básico. De modo a atingir um grau mais elevado de rigor, quando se estuda o efeito de determinadas práticas pedagógicas, será necessário impor à investigação o controlo da proficiência científica dos professores.

Para finalizar, pretende-se deixar claro que não se está à procura de um modelo que resulte em todas as circunstâncias, ou seja, que resulte em todos os contextos quaisquer que sejam as condições e sem necessidade de quaisquer adaptações. Por exemplo, pode-se começar as aulas com um 
enquadramento muito forte na selecção e mais tarde, durante o ano, quando os alunos já tiverem adquirido as regras de reconhecimento e de realização para o contexto específico daquelas aulas, pode-se então deixá-los ter algum controlo na selecção de actividades, materiais, etc. Contudo, se se pretende que alguma aprendizagem tenha lugar, a selecção nunca deve ser regulada por um enquadramento fraco.

Deve-se ainda enfatizar que tudo na investigação, que tem sido desenvolvida, indica que há características da prática pedagógica que são indispensáveis para uma boa aprendizagem e que se deverá trabalhar no sentido de as optimizar.

\section{Referências}

AFONSO, Margarida; MORAIS, Ana M. \& NEVES, Isabel P. (2002). Contextos de formação de professores: Estudo de características sociológicas específicas. Revista de Educação, vol. XI, №1, pp. 129-146.

AFONSO, Margarida; NEVES, Isabel P. \& MORAIS, Ana M. (2005). Processos de formação e sua relação com o desenvolvimento profissional dos professores: um estudo sociológico no $1^{1}$ ciclo do ensino básico. Revista de Educação, vol. XIII, no 1, pp. 5-37.

ALVES, Vanda; CALADO, Sílvia; FERREIRA, Sílvia; MORAIS, Ana M. \& NEVES, Isabel P. (2006). Instrumento de Análise do Currículo Nacional de Ciências Naturais do 3o Ciclo do Ensino Básico: Relações Intradisciplinares - Conteúdos Científicos/conteúdos metacientíficos. Lisboa: Grupo ESSA, Departamento de Educação, Faculdade de Ciências da Universidade de Lisboa.

BERNSTEIN, Basil (1990). Class, Codes and Control, vol IV: The Structuring of Pedagogic Discourse. London: Routledge.

BERNSTEIN, Basil (2000). Pedagogy, Symbolic Control and Identity: Theory, Research, Critique (ed. rev.). London: Rowman \& Littlefield.

DOMINGOS, Ana M. (presentemente MORAIS) (1987). Influência da classe social no nível de desenvolvimento científico dos alunos. Revista de Educação, Vol. I, ํo 2, pp. 55-63.

FERREIRA, Sílvia; ALVES, Vanda; CALADO, Sílvia; MORAIS, Ana M. \& NEVES, Isabel P. (2006). Instrumento de Análise do Currículo Nacional de Ciências Naturais do 3o Ciclo do Ensino Básico: Relação Ministério da Educação-Professores Critérios de Avaliação Quanto às Dimensões da Construção da Ciência. Lisboa: Grupo ESSA, Departamento de Educação, Faculdade de Ciências da Universidade de Lisboa.

FERREIRA, Sílvia (2007). Currículos de Ciências e as Ideologias dos seus Autores: Estudo Centrado no Currículo de Ciências Naturais do $3^{\circ}$ Ciclo do Ensino 
Básico. Tese de Mestrado. Lisboa: Faculdade de Ciências da Universidade de Lisboa.

MORAIS, Ana M.; NEVES, Isabel P.; MEDEIROS, Ana; PENEDA, Dulce; FONTINHAS, Fernanda \& ANTUNES, Helena (1993). Socialização Primária e Prática Pedagógica: Vol.2, Análise de Aprendizagens na Família e na Escola. Lisboa: Fundação Calouste Gulbenkian.

MORAIS, Ana M. \& NEVES, Isabel P. (2003). Processos de intervenção e análise em contextos pedagógicos. Educação, Sociedade \& Culturas, vol. 19, pp. 49-87.

MORAIS, Ana M.; NEVES, Isabel P.; SILVA, Preciosa \& DEUS, Helena (2005). What do Teachers Make of Curriculum Guidelines and Syllabuses? Study of Differential Pedagogic Practices in the Primary Science Classroom. Comunicação apresentada na 11st Conference of the European Association for Research in Learning and Instruction, Universidade do Chipre, Nicosia, Agosto.

MORAIS, Ana M. \& NEVES, Isabel P. (2005). Os professores como criadores de contextos sociais para a apredizagem científica: discussão de novas abordagens na formação de professores. Revista Portuguesa de Educação, vol. $15, n^{\circ} 2$, pp. 153-183.

MORAIS, Ana M. \& NEVES, Isabel P. (2007). Fazer investigação usando uma abordagem metodológica mista. Revista Portuguesa de Educação, vol. 20, nำ2, pp. 75-104.

NEVES, Isabel P. \& MORAIS, Ana M. (2001). Texts and contexts in educational systems: Studies of recontextualizing spaces. In A. Morais; I. Neves; B. Davies \& H. Daniels (Eds.), Towards a Sociology of Pedagogy: The Contribution of Basil Bernstein to Research. New York: Peter Lang, pp 223-249.

NEVES, Isabel P. \& MORAIS Ana M. (2005). Pedagogic practices in the family socialising context and children's school achievement. British Journal of Sociology of Education, vol. 26, nㅜ 1, pp. 121-137.

PIRES, Delmina; MORAIS, Ana M. \& NEVES, Isabel P. (2004). Desenvolvimento científico nos primeiros anos de escolaridade: estudo de características sociológicas específicas da prática pedagógica. Revista de Educação, vol. XII, n 2, pp. 119-132.

ROCHA, Carmo \& MORAIS, Ana M. (1999). Práticas pedagógicas no primeiro ciclo do ensino básico: caracterização sociológica. Revista de Educação, vol. VIII, № 1, pp. 105-122.

SANTOS, Ana (2007). Formação Inicial de Professores de Ciências: Estudo de Práticas Pedagógicas e de Aprendizagens. Tese de Mestrado. Lisboa: Faculdade de Ciências da Universidade de Lisboa.

SANTOS, Ana \& MORAIS, Ana M. (2006). Instrumento de Caracterização da Prática Pedagógica do Ensino Superior: Contexto instrucional. Lisboa: Grupo ESSA, Departamento de Educação, Faculdade de Ciências da Universidade de Lisboa.

SILVA, Preciosa; MORAIS, Ana M. \& NEVES, Isabel P. (2005). Characteristics of the Pedagogic Practice that are Crucial for Children's Scientific Learning Studying their Interplay. Comunicação apresentada na International Conference 
of the European Science Education Research Association (ESERA), Universidade Autónoma de Barcelona, Espanha, Setembro.

SILVA, Preciosa; MORAIS, Ana M. \& NEVES, Isabel P. (2003). Instrumento de Caracterização da Prática Pedagógica do Primeiro Ciclo do Ensino Básico: Contexto Instrucional. Lisboa: Grupo ESSA, Departamento de Educação, Faculdade de Ciências da Universidade de Lisboa.

\title{
EDUCATIONAL TEXTS AND CONTEXTS THAT WORK - DISCUSSING THE OPTIMIZATION OF A MODEL OF PRACTICE
}

\begin{abstract}
Along twenty years of research we have looked for answers to the major problem of improving students learning, particularly of the disadvantaged, without decreasing the level of conceptual demand. The research has been focused on various contexts: contexts of school and family learning, contexts of teacher education and contexts of syllabuses and textbooks construction. In order to direct the research and to analyse the results we have constructed specific models. Successive approximations led to a model that conceptualises a pedagogic practice that seems to have the potential to lead children to success at school, narrowing the gap between children from differentiated social backgrounds. Bernstein's theory of pedagogic discourse has provided the main theoretical framework to our studies. This article intends to present the model and describe its characteristics, to show the model at work and to discuss its optimization. A new improved theoretical model, derived from that optimization, will be tested in future research.
\end{abstract}

Keywords

Pedagogic practice; Students learning; Social contexts 


\title{
TEXTES ÉDUCATIFS ET CONTEXTES FAVORISANT L'APPRENTISSAGE - OPTIMISATION D'UN MODĖLE DE PRATIQUE PÉDAGOGIQUE
}

\begin{abstract}
Résumé
Tout du long de vingt ans d' investigation, on a cherché des réponses pour le problème d' améliorer l' apprentissage des élèves, particulièrement de ceux qui ne sont pas favorisés, sans amoindrir le niveau d'exigence conceptuel. L' investigation s' a fait ressortir en plusieurs contextes: contextes d' apprentissage dans la famille et dans l' école, contextes de formation de professeurs et contextes d' élaboration (de construction ) de programmes et de manuels scolaires. De façon à guider l' investigation et a faire l' analyse des résultats, nous avons construit des modèles spécifiques. Les rapprochements successives on conduit à un modèle qui conceptualise une pratique pédagogique qu' on dirait avoir le potenciel pour amener les élèves jusqu' au succès scolaire, amoindrissant le fosse parmis les élèves socialement différentiés. Les études ont eu comme encadrement conceptuel essentiel la théorie du discours pedagogique de Bernstein. Dans cet article on veut présenter le modèle et faire la description de ses caractéristiques, faire voir les façons comme il a été usité et discuter son efficace. Un nouveau modèle théorique, dérivé de cet efficace, serra épreuvé dans une investigation à l' avenir.
\end{abstract}

Mots-clé

Pratique pédagogique; Apprentissage des élèves; Contextes sociaux

Recebido em Outubro/2008

Aceite para publicação em Fevereiro/2009

Toda a correspondência relativa a este artigo deve ser enviada para: Ana Maria Morais, e-mail: ammorais@fc.ul.pt; Isabel Neves, e-mail: imneves@fc.ul.pt 


\section{Anexos}

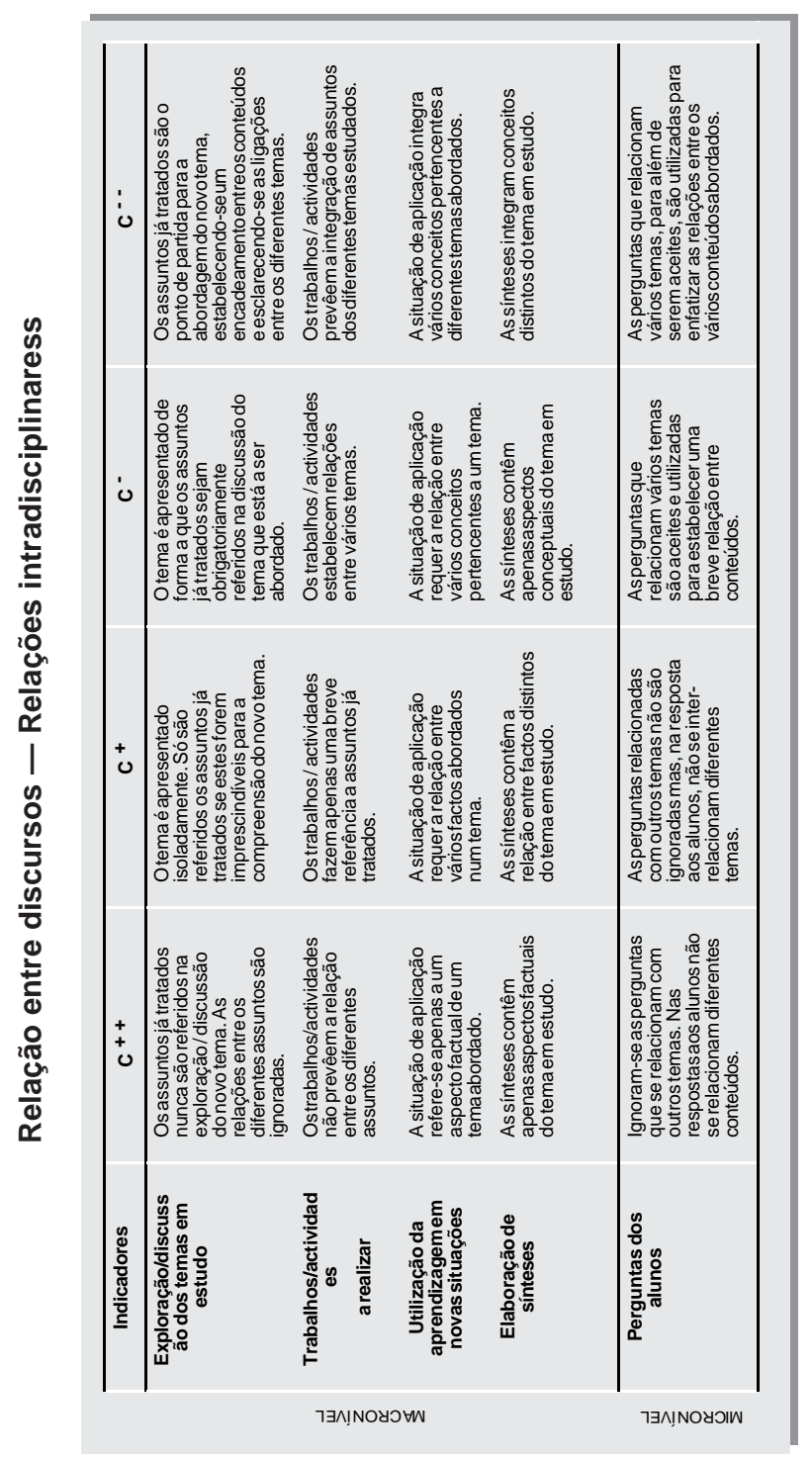


28 Ana Maria Morais \& Isabel Pestana Neves

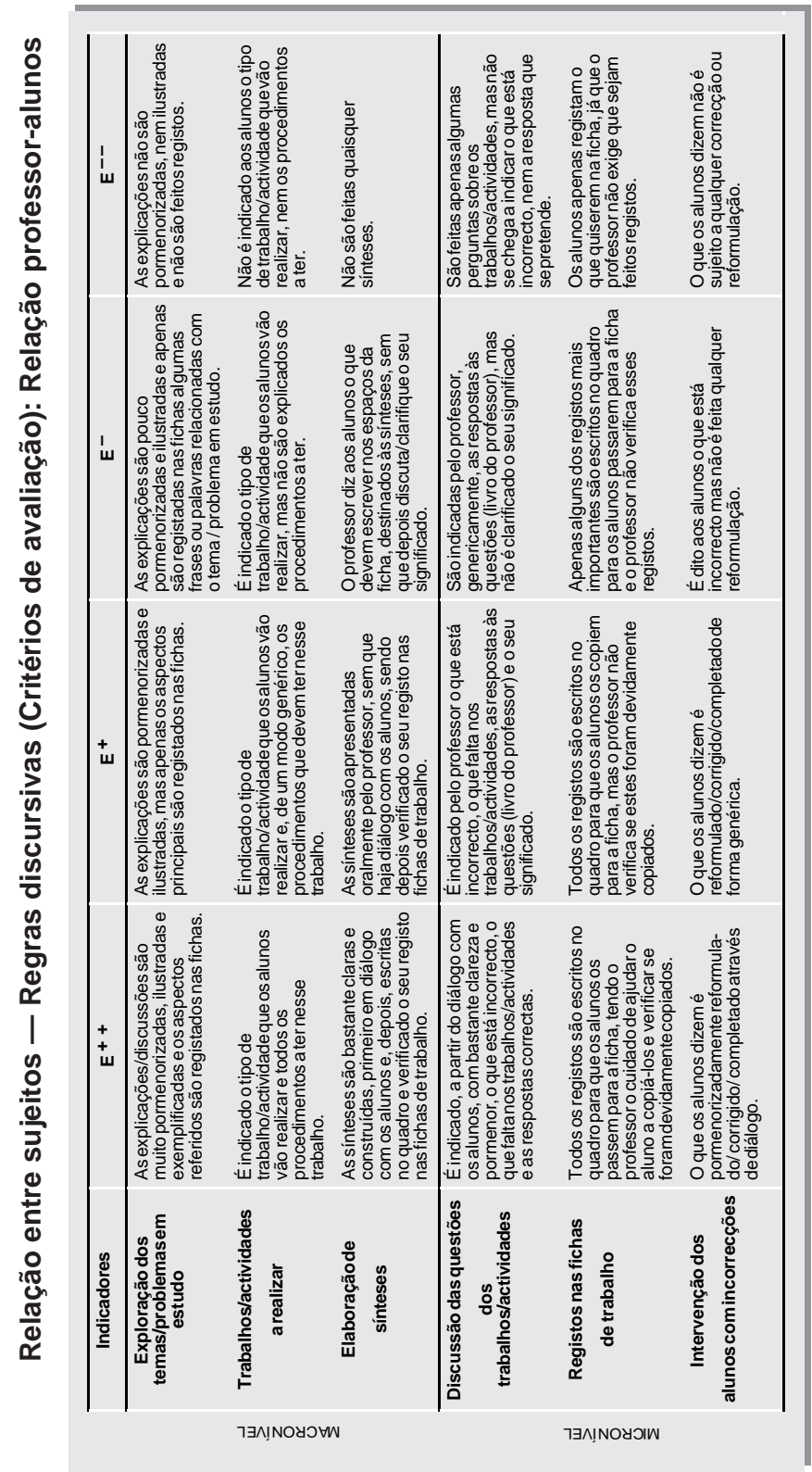

